\title{
Potential for improvement of population diet through reformulation of commonly eaten foods
}

Joop van Raaij*, Marieke Hendriksen and Hans Verhagen

National Institute for Public Health and the Environment (RIVM), PO Box 1, 3720 BA Bilthoven, The Netherlands

Submitted 1 November 2007: Accepted 24 June 2008: First published online 1 August 2008

\begin{abstract}
Food reformulation: Reformulation of foods is considered one of the key options to achieve population nutrient goals. The compositions of many foods are modified to assist the consumer bring his or her daily diet more in line with dietary recommendations.

Initiatives on food reformulation: Over the past few years the number of reformulated foods introduced on the European market has increased enormously and it is expected that this trend will continue for the coming years.

Limits to food reformulation: Limitations to food reformulation in terms of choice of foods appropriate for reformulation and level of feasible reformulation relate mainly to consumer acceptance, safety aspects, technological challenges and food legislation.

Impact on key nutrient intake and bealth: The potential impact of reformulated foods on key nutrient intake and health is obvious. Evaluation of the actual impact requires not only regular food consumption surveys, but also regular updates of the food composition table including the compositions of newly launched reformulated foods.
\end{abstract}

Keywords

Food reformulation

Key nutrients

Health impact
In 2003 a Joint WHO/FAO Expert Consultation ${ }^{(1)}$ provided population goals for nutrients consistent with the prevention of major public health problems in Europe. These goals include a reduction of total dietary fat, in particular of saturated fat, a reduction in trans fatty acids, an increase in PUFA, a reduction in sugar consumption and a reduction in salt intake. Reformulation of commonly eaten foods was considered one of the key options to achieve these goals ${ }^{(2)}$.

Leading companies report to have recently reformulated at least $50 \%$ of their products and claim to have put more than 4000 new or reformulated products on the market over the past 3 years ${ }^{(3)}$. There are also impressive ongoing national campaigns on food reformulation such as the campaigns on salt reduction by governmental agencies in England, Ireland, France and Finland.

Whether the consumer will indeed choose for reformulated foods and a lower salt consumption remains to be seen. Only when actual consumption figures are known can the relevance of reformulated foods with respect to dietary goals and health impact be indicated.

The present paper starts with a description of developments in dietary recommendations and the concept and definition of food reformulation. Subsequently, important current initiatives on food reformulation are presented, main limitations in terms of choice of appropriate foods for reformulation and level of feasible reformulation are clarified, and the potential impact of reformulated foods on key nutrient intake and health is discussed.

\section{Developments in dietary recommendations}

In the second half of the 20th century, political and socioeconomic developments in Europe resulted in a more secure and abundant food supply than ever before and life expectancy increased steadily. However, at the same time a huge increase in several chronic diseases was observed, and it was recognized that these chronic diseases could be linked to dietary and lifestyle factors. In 2003 a Joint WHO/ FAO Expert Consultation ${ }^{(1)}$ provided an overview of the strength of evidence for dietary factors related to undesirable health outcomes. There was strong evidence that the levels of trans fatty acids, SFA, Na and sugars were too high in the European diet. Based on this information, the Joint WHO/ FAO Expert Consultation worked out population nutrient intake goals, which are population average intakes that are judged to be consistent with the maintenance of health in a population. These population nutrient goals (see Table 1) might be used in developing healthier food choices.

\section{Healthier food choices}

The concept of healthy food is quite confusing. The healthiness of a food depends upon how much we eat of 
Table 1 Population nutrient intake goals ${ }^{(1)}$

\begin{tabular}{ll}
\hline Dietary factor & \multicolumn{1}{c}{ Goal } \\
\hline Total fat & $15-30 \%$ of energy \\
SFA & $<10 \%$ of energy \\
Trans fatty acids & $<1 \%$ of energy \\
Total carbohydrate & $55-75 \%$ of energy \\
Free sugars & $<10 \%$ of energy \\
$\mathrm{Na}$ & $<2 \mathrm{~g} / \mathrm{d}^{*}$ \\
\hline
\end{tabular}

${ }^{\star}$ Equivalent to salt intake of $<5 \mathrm{~g} / \mathrm{d}$.

it, how often, what our nutritional needs are, and what else we eat in the diet. There is no single complete food that provides all the nutrients we need. Therefore, a variety of foods in the diet and watching portion size remain the keys to a healthy diet. Eating a healthy diet will reduce the risk of diseases such as CVD, cancer, obesity and type 2 diabetes mellitus.

Taking care to consume of a variety of foods in appropriate portion sizes in the daily diet might imply a substantial change in consumer's dietary behaviour. This might be realized through education, information and communication on promoting of eating more fruits, vegetables and fish, and on stimulating to eat less salt, sugar, fat, saturated fat and 'empty calories'.

An additional way to help the consumer make the healthy choice the easy choice is by improving the composition of commonly eaten foods. The advantage of this approach is that the impact on key nutrient intakes might be expected in the shorter term, since the consumer does not have to modify drastically his or her habitual dietary food pattern.

\section{Food reformulation}

In the context of healthier food choices, food reformulation might be defined as reformulating existing foods to remove (e.g. trans fatty acids) or reduce (e.g. sugars, saturated fat, salt) certain food components while maintaining characteristics such as flavour, texture and shelflife. In 2004 the WHO Global Strategy on Diet, Physical Activity and Health ${ }^{(2)}$ recommended the private sector to limit the levels of trans fatty acids, SFA, salt and free sugars in existing products. From the early 1990s onwards companies started eliminating trans fatty acids from their products, but especially in the first decade of this century the private sector implemented many initiatives on food reformulation.

Reformulation aiming at a healthier composition is usually focused on nutrients associated with negative health effects (too much trans fatty acids, SFA, salt, and free sugars), but reformulation might also very well focus on maintaining of nutrients associated with positive health effects (e.g. fibre, vitamins, minerals) that are normally removed during processing (e.g. when flour is milled, thereby removing bran and germ).
The recent interest for healthier foods also resulted in the development of foods to which 'positive' nutrients and ingredients (such as vitamins, minerals, phytosterols and phytostanols, pro- and prebiotics) are added in substantial amounts. Such foods, to which often specific healthpromoting effects are ascribed, are known as functional foods and functional food ingredients. Obviously, such products are not similar to the concept of reformulated foods meant above. Food reformulation should also not be mixed up with food enrichment (addition of nutrients to foods in accordance with a standard of identity as defined by food regulations), with food supplementation (addition of nutrients that are normally not present in the food or only in minimal quantities) or with food fortification (fortification has a special meaning: the nutrient added and the food chosen as a carrier have met certain criteria, so that the fortified product will become a good source of the nutrient for a targeted population; nutrients added for food fortification may or may not have been present in the food carrier originally).

\section{Initiatives on food reformulation}

Initiatives on food reformulation should preferably focus on basic foods commonly eaten by all socio-economic classes of a population. Basic foods belong to one of the main categories of foods: cereals and cereal products, fruits and vegetables, meat and fish and eggs, milks and milk products, fats and oils, and beverages. Reformulation does not really apply to fruits and vegetables, and neither to fish. The composition of various animalderived foods such as milk and meat can be improved by modified animal feed ${ }^{(4)}$. This reformulation focuses on partly replacing saturated by unsaturated fatty acids. The private sector has just started to work on these options and more research is still needed. As far as we know eggs have not yet been reformulated to make them healthier. For the other main categories of commonly eaten foods interesting initiatives have been launched and implemented. These initiatives arise spontaneously, but sometimes they are mandated by legislation (e.g. with respect to trans fatty acids) or they originate in negotiation with public health agencies (e.g. with respect to salt reduction). It would be interesting to map out the motives behind reformulation initiatives.

Table 2 shows an overview of initiatives mainly based on data from the Confederation of the Food and Drink Industries of the $\mathrm{EU}^{(3)}$. The table can be considered a representative reflection of ongoing initiatives, but is certainly not exhaustive. Unfortunately, the table cannot be completed with numbers of ongoing initiatives since such information has not yet been collected systematically. However, it might be assumed that the table will become more complete in the near future since innovative processes will lead to more reformulated foods in more food categories. 


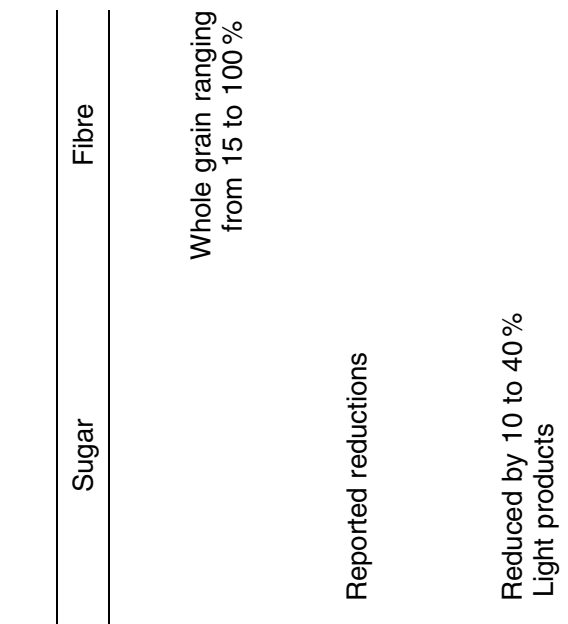

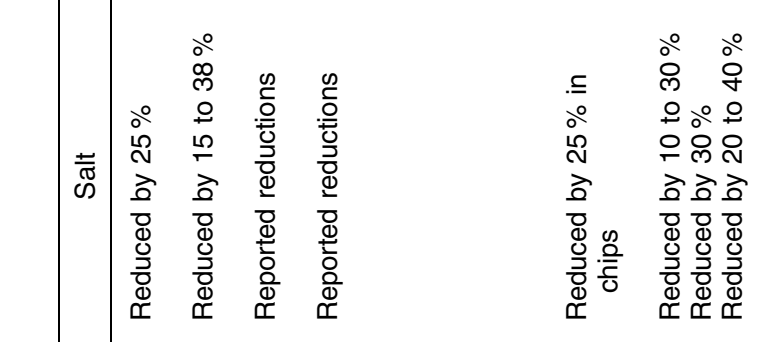


what might be achieved in terms of nutrient reformulation.

1. Consumer acceptance. Although consumers can get accustomed to a less salty or sweet taste, this can only be achieved by a gradual salt and sugar reduction over a certain time frame, maybe several years. When the salt reduction is too fast and the accompanying taste not acceptable to consumers, the products will be no longer bought.

2. Safety aspects. Salt is also used as a preservative and salt reduction might lead to reduced shelf-life. Salt reduction may require new technological processing approaches to ensure the safety of the products.

3. Technological challenges. In the past, trans and saturated fat were important to the hardness that made margarines functional. New developments in packaging made new developments possible. Tubs allowed packaging of softer margarines that could not have been held in the classic wrapper. New technology on structuring of fats made it possible to maximize liquid oils and minimize 'hardstock' (the technological term for hard fats) ${ }^{\text {(13) }}$. It should be realized that fats and sugars also have technological properties that contribute to structural characteristics of the products ${ }^{(13,14)}$. This implies that a certain amount of these nutrients are required in a product, until technological innovations take place.

4. Food legislation. Food legislation also steers reformulation. For example, certain cheese should be made from full-fat cow's milk, as described in the Commodities Act. So, food legislation might limit the options for reformulation.

The present reformulated products have not yet achieved their limits in terms of taste, safety and technological challenge. A lot of work still might be performed to explore the real limits. Another important issue concerns the possible risks of reformulation. For example, are the expected increases in intakes of flavourings (e.g. because of reducing salt levels) and sweeteners (e.g. because of reducing sugar levels) indeed harmless? Does replacement of certain nutrients by others really result in a healthier product? For example, replacement of saturated fat by sugar or trans fat by saturated fat does not automatically result in a healthier food.

\section{Evaluation of foods and beverages for their nutritional composition}

A lot of initiatives on reformulation have been implemented and this should be regarded as a very positive development. However, to what level does a food or beverage have to be reformulated before it can be considered a healthier choice? To answer that question a method is needed to evaluate foods and beverages for their nutritional composition.
Nutrient profiling categorizes foods according to their nutritional composition ${ }^{(15)}$. Several companies such as Unilever, Danone, PepsiCo, Nestlé and Kraft have developed their own evaluation method, as have non-profit organizations and universities ${ }^{(16)}$. Early in 2008 the European Food Safety Authority published nutrient profiles within the framework of EU Regulation 1924/2006 on Nutrition and Health Claims on Foods ${ }^{(17)}$. Unfortunately, all of these methods use different approaches. Several scientific methods have been used to validate various nutrient profiles ${ }^{(18,19)}$, but all of them have their limitations.

\section{Potential impact of reformulated foods on key nutrient intake}

When reformulated foods indeed can be considered a healthier choice, then it should be checked whether the total of reformulated foods might indeed result in intakes of key nutrients in line with recommendations. Such a check can be performed in five steps.

1. Information should be collected in the country on representative daily diets or menus. Such information might be obtained through national food consumption surveys.

2. In the next step the intake of key nutrients from these representative daily diets or menus should be calculated using the national food composition table.

3. In the modelling process the regular foods in the daily diets and menus should be replaced by their reformulated alternatives.

4. Subsequently, the intake of key nutrients from the daily diets and menus with the reformulated foods should be calculated using a food composition table to which the compositions of the new reformulated foods have been added.

5. Finally, obtained intakes of key nutrients from step 2 and step 4 should be compared with each other and with the recommendations.

With such a calculation procedure the impact of reformulated foods on key nutrient intake can be assessed and evaluated. It is clear that such considerations can only be made if up-to-date information is available from food consumption surveys, if up-to-date market information is available on recently launched reformulated foods, and if the compositions of new reformulated foods are known and included in up-to-date food composition tables.

Unfortunately, such exercises on the impact of reformulated foods on key nutrient intake have not yet been published. However, a comparable exercise was performed recently on the impact of products with the Choices logo. Foods that fulfil the benchmarks behind the Choices programme ${ }^{(20)}$ (benchmarks for the four nutrients: trans fat, saturated fat, $\mathrm{Na}$ and added sugar) may 
Table 3 Potential impact on key nutrient intake of replacing regular foods in the Dutch daily diet by Choices foods (modified after Jansen ${ }^{(21)}$ )

\begin{tabular}{llccr}
\hline Nutrient & $\begin{array}{c}\text { WHO } \\
\text { recommendations }\end{array}$ & $\begin{array}{c}\text { Daily nutrient intakes } \\
\text { based on Dutch Survey* }\end{array}$ & $\begin{array}{c}\text { Daily nutrient intakes from } \\
\text { typical Dutch daily menust }\end{array}$ & $\begin{array}{c}\text { Daily nutrient intakes } \\
\text { from Choices menusł }\end{array}$ \\
\hline Energy (kcal/d) & $2000-2500$ & 2190 & 2119 & 1783 \\
SFA (\% of energy) & $<10$ & $14 \cdot 2$ & $15 \cdot 7$ & $8 \cdot 4$ \\
Trans fatty acids (\% of energy) & $<1$ & $1 \cdot 7$ & $1 \cdot 2$ & $0 \cdot 1$ \\
Free sugars (\% of energy) & $<10$ & $15 \cdot 5$ & $13 \cdot 2$ & $5 \cdot 6$ \\
Fibre (g/d) & $>25$ & 21 & 18 & 25 \\
Na (mg/d) & $<2400$ & 2785 & 2858 & 2335
\end{tabular}

*Derived from Dutch National Dietary Survey $1998^{(27)}$; free sugar=added sugar (added sugars are derived from total sugars by assuming that two-thirds of total sugars are composed of added sugars).

+Values represent mean values from three typical Dutch daily menus (typical Dutch daily menus were based upon information from the Dutch National Dietary Survey $\left.1998^{(27)}\right)$.

$\ddagger$ Values represent mean values from the same three typical Dutch daily menus in which the regular foods have been replaced by their Choice alternatives.

apply for the logo. Based upon the Dutch Food Consumption Survey 1998, three representative daily menus composed of regular foods were derived. The intakes of macro- and micronutrients with these daily menus were calculated using the Dutch Food Composition Table 1998 (Table 3). In order to calculate the nutrient intake with Choices foods, the regular foods within the three menus were replaced by foods with the Choices logo. As shown in Table 3, a full replacement of regular foods by Choices foods in representative Dutch daily menus implies that dietary guidelines would already be achieved ${ }^{(21)}$. Although the Choices foods include reformulated foods, its assortment is broader. However, this Choices example demonstrates the feasibility of this approach for a similar exercise with just formulated products.

Of course, such modelling exercises should be based upon realistic scenarios. For example, it is not realistic to assume that consumers will fully replace regular products in their diet by available reformulated products as long as the manufacturers and retailers continue selling the regular foods as well. It would be commendable if manufacturers would withdraw their regular products from the market as soon as they have launched reformulated products. Another point of concern relates to the selling price of reformulated products, which preferably should not be higher than that of regular products. The public sector as well as industry and retailers should make efforts to make the consumer aware of the importance of reformulated products.

\section{Potential impact of reformulated foods on health}

Once the actual (key) nutrient intakes with new and reformulated products have been calculated, the potential health gains in terms of disease, death, disability-adjusted life years (DALY; a summary measure which combines death and illness, using a disability weighing factor for the seriousness of the disease), life expectancy and diseasefree life expectancy can be calculated. As far as we are aware, such modelling calculations have not yet been performed and published in relation to reformulated foods. The approaches and methodologies that might be used are available ${ }^{(22)}$. In The Netherlands, the National Institute for Public Health and the Environment (RIVM) has developed a Chronic Diseases Model that can be used to estimate the long-term health effects and related health-care costs of dietary interventions ${ }^{(23)}$. Recent simulations for the Dutch situation show that large health gains are still to be achieved by increased consumption of fruits, vegetables and fish, but that most health benefits related to fatty acid composition have already been realized $^{(24)}$. Unfortunately, the present Chronic Disease Model is not yet appropriate for simulations on health effects of modifications in fibre, salt and added sugar content.

There are also examples of food reformulation that have demonstrated their positive influence on health, such as the Finland salt initiative. Since the 1970s, national regulation came into force for labelling foods low and high in salt. The food industry developed products low in salt as part of the community strategy, and removed products high in salt from the market. Over the period 1979-2002 the level of $24 \mathrm{~h}$ urinary $\mathrm{Na}$ excretion in Finland decreased significantly ${ }^{(25)}$. Pietinen et al. ${ }^{(26)}$ concluded that labelling the salt content in foods is a useful approach to reduce $\mathrm{Na}$ intake. The decline in salt intake probably explains the drop in blood pressure levels observed among the Finnish population since the 1970s. This Finnish example strongly suggests that making the food supply healthier might reduce the incidence of a chronic disease.

\section{Conclusion}

In summary, reformulation of foods is quite rightly considered a key option to achieve population nutrient goals. In the coming years more reformulated products will be placed on the market. The choice of appropriate foods to reformulate within the various food categories is not yet exhausted and also the level to which reformulation can be applied in individual foods has not yet reached its limit. Whether the consumer will really choose reformulated products will depend on what has been achieved in terms of nutritional education, information and communication, 
but will also depend upon the selling price and whether the original foods are still on the market. Appropriate monitoring of the consumption of reformulated foods remains essential to evaluate the impact of reformulated foods on key nutrient intake. This not only implies regular food consumption surveys but also regular updates of the food composition table with the compositions of the launched reformulated foods. To study the direct impact of food formulation on for example the incidence rates of chronic diseases is quite difficult, but with modelling and scenario development the potential health gains in terms of disease, death, DALY, life expectancy and disease-free life expectancy might be approached.

\section{Acknowledgements}

The study was financed by the authors' organization: the National Institute for Public Health and the Environment (RIVM).

Conflict of interest: For all authors there are no conflicts of interest.

Author contributions: J.v.R., M.H. and H.V. contributed equally to information collection, interpretation of data, and writing the article.

\section{References}

1. World Health Organization (2003) Diet, Nutrition and the Prevention of Chronic Diseases. Joint WHO/FAO Expert Consultation. WHO Technical Report Series no. 916. Geneva: WHO.

2. World Health Organization (2004) Global Strategy on Diet, Physical Activity and Health. Fifty-seventh World Health Assembly. Geneva: WHO.

3. Confederation of the Food and Drink Industries of the EU (2007) Promoting balanced diets and healthy lifestyles: Europe's food and drink industry in action. http://www. ciaa.be/documents/brochures/CIAA_Rapport_commitments. pdf (accessed September 2007).

4. Givens DI (2005) The role of animal nutrition in improving the nutritive value of animal-derived foods in relation to chronic disease. Proc Nutr Soc 64, 395-402.

5. Campina (2007) Welkom bij Campina/De oorsprong van de nóg gezondere melk (Welcome to Campina/The origin of even healthier milk). http://www.campina.nl/default.aspx? selected $=$ campina.nl.nieuwemelk (accessed September 2007).

6. European Dairy Industry (2007) About the European Dairy Industry: Developments. http://www.euromilk.org/eda/ content_html.aspx?cid=11 (accessed September 2007).

7. Food Standards Agency, UK (2007) Development of salt targets. http://www.food.gov.uk/healthiereating/salt/devsalttargets (accessed September 2007).

8. Food Standards Agency, UK (2007) Progress with industry in relation to salt reduction. http://www.food.gov.uk/ healthiereating/salt/Saltprogressstatement/ (accessed September 2007).

9. Larsson I, Lissner L \& Wilhelmsen L (1999) The 'Green Keyhole' revisited: nutritional knowledge may influence food selection. Eur J Clin Nutr 52, 776-780.

10. National Food Administration of Sweden (2008) The Keyhole Symbol. http://www.slv.se/templates/SLV_Page. aspx?id $=2581 \&$ epslanguage $=$ EN-GB (accessed April 2008).
11. Department of Health, France (2006) Second National Nutrition and Health Programme 2006-2010. http://www. sante.gouv.fr/htm/pointsur/nutrition/index.htm (accessed April 2008).

12. Department of Health, France (2006) Standard Reference document. For voluntary undertakings charters of commitments of nutritional improvement drawn up by food sector operators under the National Nutrition and Health Programme 2. http://www.sante.gouv.fr/htm/pointsur/nutrition/ index.htm (accessed April 2008).

13. Korver O \& Katan MB (2006) The elimination of trans fats from spreads: how science helped to turn an industry around. Nutr Rev 64, 275-279.

14. Eckel RH, Borra S, Lichtenstein AH \& Yin-Piazza SY (2007) Understanding the complexity of trans fatty acid reduction in the American diet: American Heart Association Trans Fat Conference 2006: report of the Trans Fat Conference Planning Group. Circulation 115, 2231-2246.

15. Rayner M, Scarborough P \& Stockley L (2004) Nutrient Profiles: Options for Definitions for Use in Relation to the Promotion of Foods to Children. London: Food Standards Agency; available at http://www.food.gov.uk/multimedia/ pdfs/Nutrientprofilingpullreport.pdf (accessed September 2007).

16. Drewnowski A (2007) What's next for nutrition labeling and health claims? An update on nutrient profiling in the European Union and the United States. Nutr Today $\mathbf{4 2}$, 206-214.

17. European Food Safety Authority (2008) The setting of nutrient profiles for foods bearing nutrition and health claims pursuant to article 4 of the Regulation (EC) No 1924/ 2006. EFSA J 644, 1-44.

18. Azaïs-Braesco V, Goffi C \& Labouze E (2006) Nutrient profiling: comparison and critical analysis of existing systems. Public Health Nutr 9, 613-622.

19. Scarborough P, Rayner M \& Stockley L (2007) Developing nutrient profile models: a systematic approach. Public Health Nutr 10, 330-336.

20. Choices International Foundation (2008) Qualifying criteria. http://www.choicesinternational.org/index.php?option = com_ content\&task $=$ view\&id $=31$ \&Itemid $=54$ (accessed April 2008).

21. Jansen L (2007) Scherpere criteria voor meer productgroepen; achtergronden bij de nieuwe criteria voor Ik Kies Bewust-logo (Stricter criteria for more product groups; background on the new criteria for the Choices logo). Voeding $N u$ 4, 21-23.

22. van Kreijl CF, Knaap AGAC \& van Raaij JMA (editors) (2006) Our Food, Our Health: Health Diet and Safe Food in The Netherlands. Bilthoven: RIVM.

23. Hoogenveen RT, de Hollander AEM \& van Genugten MLL (1998) The Chronic Diseases Modelling Approach. Bilthoven: RIVM.

24. Büchner FL, Hoekstra J, van den Berg SW, Wieleman F \& van Rossum CTM (2007) Kwantificeren van de gezondbeidseffecten van voeding (Quantifying Health Effects of Nutrition). Report no. 350080001/2007. Bilthoven: RIVM.

25. Laatikainen T, Pietinen P, Valsta L, Sundvall J, Reinivuo H \& Tuomilehto J (2006) Sodium in the Finnish diet: 20-year trends in urinary sodium excretion among the adult population. Eur J Clin Nutr 60, 965-970.

26. Pietinen P, Valsta LM, Hirvonen T \& Sinkko H (2008) Labelling the salt content in foods: a useful tool in reducing sodium intake in Finland. Public Health Nutr 11, 335-340.

27. Netherlands Nutrition Centre (1998) Zo eet Nederland. Resultaten van de Voedselconsumptiepeiling 1997-1998 (Results of the Dutch Food Consumption Survey 1997-1998). Den Haag: Netherlands Nutrition Centre. 